This item was submitted to Loughborough's Research Repository by the author.

Items in Figshare are protected by copyright, with all rights reserved, unless otherwise indicated.

\title{
Monitoring continuous crystallization of paracetamol in the presence of an additive using an integrated PAT array and multivariate methods
}

PLEASE CITE THE PUBLISHED VERSION

http://dx.doi.org/10.1021/acs.oprd.5b00373

\section{PUBLISHER}

(C) American Chemical Society

\section{VERSION}

AM (Accepted Manuscript)

\section{PUBLISHER STATEMENT}

This work is made available according to the conditions of the Creative Commons Attribution-NonCommercialNoDerivatives 4.0 International (CC BY-NC-ND 4.0) licence. Full details of this licence are available at: https://creativecommons.org/licenses/by-nc-nd/4.0/

\section{LICENCE}

CC BY-NC-ND 4.0

\section{REPOSITORY RECORD}

Powell, Keddon, Ali N. Saleemi, Chris Rielly, and Zoltan Nagy. 2016. "Monitoring Continuous Crystallization of Paracetamol in the Presence of an Additive Using an Integrated PAT Array and Multivariate Methods". figshare. https://hdl.handle.net/2134/21978. 


\title{
Monitoring Continuous Crystallization of Paracetamol in the Presence of an Additive Using an Integrated PAT Array and Multivariate Methods
}

\author{
Keddon A. Powell, ${ }^{\dagger \dagger}$ Ali N. Saleemi, ${ }^{\ddagger}$ Chris D. Rielly, ${ }^{\dagger}$ and Zoltan K. Nagy ${ }^{*}{ }^{\dagger}, \S$ \\ ${ }^{\dagger}$ EPSRC Centre for Innovative Manufacturing in Continuous Manufacturing and Crystallization at the Department of Chemical \\ Engineering, Loughborough University, Loughborough, Leicestershire LE11 3TU, U.K. \\ ${ }^{\ddagger}$ GSK, Gunnels Wood Road, Stevenage, Hertfordshire, SG1 2NY, U.K. \\ ${ }^{\S}$ School of Chemical Engineering, Purdue University, West Lafayette, Indiana 47907, United States
}

ABSTRACT: In this study, an automated intelligent decision support (IDS) framework was applied to monitor the continuous crystallization of form I paracetamol (PCM) and determine steady-state operation. A modified single-stage mixed suspension mixed product removal (MSMPR) crystallizer was used to investigate methods to minimize early onset of fouling and encrustation by carrying out crystallizations in the presence and absence of hydroxyl propyl methyl cellulose (HPMC) additive. The effectiveness of HPMC toward controlling the crystallization process and alleviating fouling and encrustation for prolonged operation of the MSMPR was investigated over a range of concentrations. HPMC was found to suppress nucleation and growth, thereby controlling the crystallization and alleviating fouling and encrustation over extended operating periods. HPMC also affected the product crystal morphology, leading to predominantly tabular shaped crystals. Steady state in the MSMPR was characterized using the IDS, which consisted of an integrated and ancillary array of process analytical technologies (PAT), including the application of Raman spectroscopy with multivariate calibration for solution phase concentration measurement.

\section{INTRODUCTION}

The operation of batch crystallizers currently employed in pharmaceutical and other high-value chemical industries is often labor-intensive, costly, and inefficient. High-level modeling, monitoring, and control strategies are increasingly being developed using process analytical technologies (PAT) to improve batch crystallizer performance. However, similar concepts can be applied to continuous crystallizers, gaining the additional benefits related to operating at steady state ${ }^{1-4}$ or at least in a controlled dynamic state. There exist significant opportunities to apply PAT to tailor desired product critical quality attributes (CQA) such as crystal size distribution (CSD), shape distribution, and purity in the continuous crystallization domain. This could likely lead to the development of scalable and adaptable continuous crystallizers to meet current manufacturing challenges, such as reduced product and process variability, reduced inventory levels, and lower manufacturing costs. Furthermore, PAT tools are essential for real-time process monitoring and control, as they supply the data from which relevant process and product information and conclusions can be extracted. ${ }^{5,6}$ In addition to applying PAT for process monitoring and control, novel continuous crystallization operating strategies are required to overcome the limitations of current technologies. For example, fouling and encrustation, transfer line blockage, and classified product withdrawal issues are frequently experienced in the $\mathrm{MSMPR}^{7-11}$ and tubular flow crystallizer. ${ }^{12-14}$ Fouling and encrustation and transfer line blockage are often the result of the development of high local supersaturation due to temperature differences within the crystallizer, leading to uncontrolled nucleation events and encrustation on heat exchange surfaces. ${ }^{2,15,16}$ In addition, surface properties of the crystallizer construction material (such as roughness) are known to contribute to encrustation issues. ${ }^{16,17}$ The breaking off of crusts from the crystallizer walls can then lead to line blockages as well as particle settling and classification due to the difference in flow velocities in the agitated crystallizer or in transfer lines. To overcome these challenges in MSMPR operation, researchers have used different operating strategies to varying degrees of success, for example, intermittent withdrawal $^{9,18,19}$ and, more recently, periodic flow operation. ${ }^{20}$ In this study, a two-pronged approach was taken to alleviate fouling and encrustation in MSMPR. The first involved the design of a modified MSMPR, incorporating a baffled heat exchanger to minimize temperature variations that can occur when incoming feed solution at higher temperature enters the MSMPR operating at lower temperature. Fouling and encrustation occur by the following mechanisms: (1) adsorption onto a surface prone to fouling/encrustation, (2) adsorption on heterogeneous and secondary nuclei that come into contact with the surface, and (3) alteration of the surface structure of the nuclei and crystals. ${ }^{17}$ The second approach to fouling and encrustation prevention involved the use of an additive to control the crystallization kinetics. The polymer hydroxyl propyl methyl cellulose (HPMC) was identified as a possible candidate. In their study, Femi-Oyewo et al. ${ }^{21}$ investigated the effect of additives on the crystallization of PCM from aqueous solution and in particular on the crystal structure and processability of PCM raw material in the final

Received: November 10, 2015 


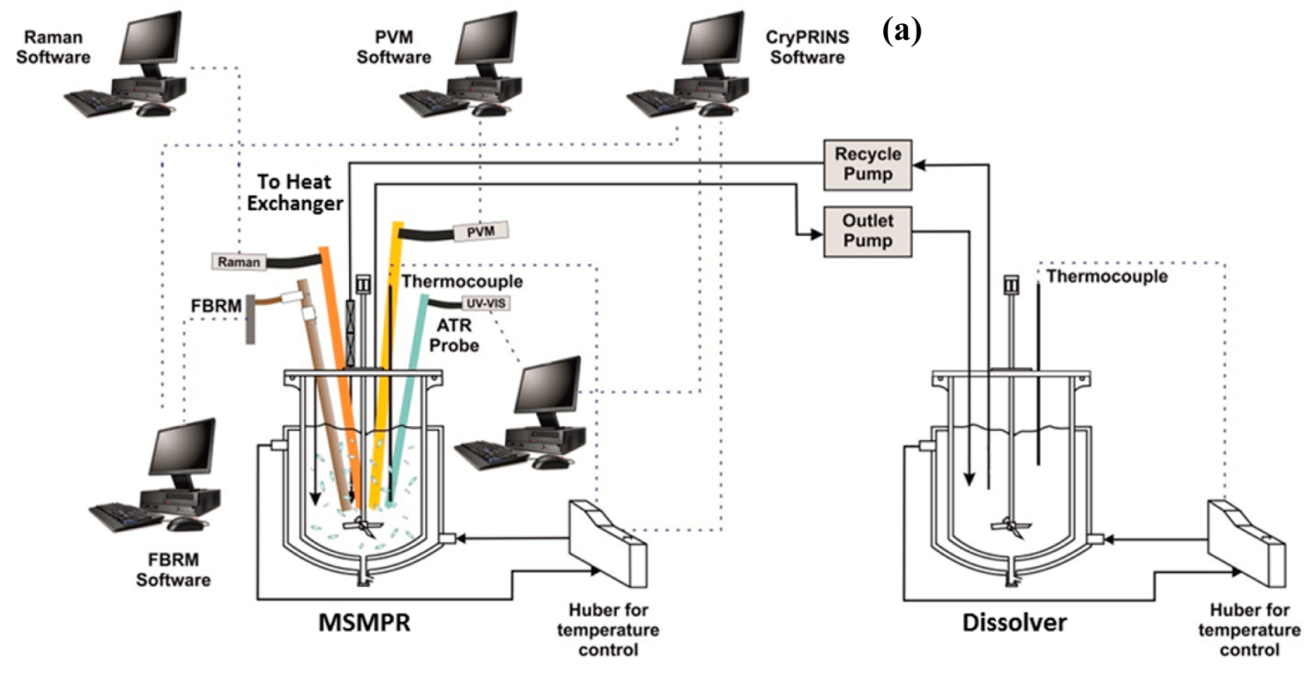

(b)

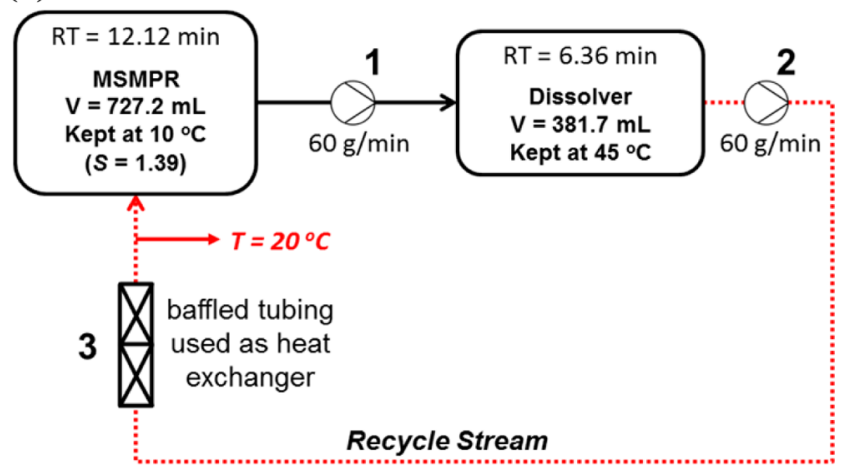

(c)

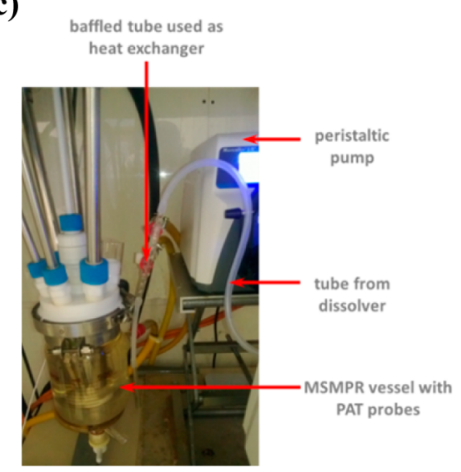

Figure 1. (a) Schematic of modified single-stage MSMPR unit with integrated PAT array and CryPRINS information system tools used for process monitoring and implementation of temperature control. (b) Flow diagram of MSMPR indicating the operating conditions employed. (c) Photograph of the lab-scale MSMPR used for the continuous cooling crystallization of PCM.

solid dosage form. HPMC was found to significantly suppress nucleation and growth of PCM in the concentration range 0.1$0.7 \mathrm{wt} \%$, resulting in very fine crystals. In the current study, the aim was to control the crystallization (nucleation and growth) of PCM to avoid fouling and encrustation for prolonged operation of the modified MSMPR. Concentrations of HPMC less than $0.1 \mathrm{wt} \%$ were investigated to avoid significant suppression of nucleation and crystal growth.

A further aim of the work presented here is to demonstrate how the development and application of a robust monitoring framework using PAT in combination with multivariate methods and information systems tool may be applied to characterize the modified MSMPR crystallizer. For this purpose, an automated integrated intelligent decision support system (IDS) consisting of three components was used: (1) an integrated PAT array based on attenuated total reflectance ultraviolet/visible (ATR-UV/vis) spectroscopy and focused beam reflectance measurement (FBRM), (2) a crystallization process informatics software system (CryPRINS), and (3) an ancillary PAT array based on Raman spectroscopy and particle vision microscopy (PVM). These tools were applied to monitor crystallizations in the modified MSMPR and determine when steady state (or a "state of controlled operation" ${ }^{20}$ ) is achieved. The IDS allowed for real-time temperature control using RS232 communication between CryPRINS and the thermofluid baths used to supply coolant to the MSMPR heat transfer jacket.
Until now, integrated PAT array and information systems tools have primarily been applied to batch crystallizers. ${ }^{22-24}$ In their study, Saleemi et al. ${ }^{23}$ demonstrated the use of an integrated PAT array consisting of ATR-UV/vis, FBRM, and the CryPRINS information systems software within an IDS framework to monitor and control the crystallization of mixtures of positional isomers. $\mathrm{Wu}$ and $\mathrm{Khan}^{24}$ used an integrated PAT framework consisting of near-infrared spectroscopy (NIR), FBRM, and a turbidity sensor to monitor a coprecipitation process. These investigators concluded that the use of integrated PAT array and information systems were essential for knowledge building and process understanding and for establishing suitable process monitoring and control strategies. In addition to providing real-time process monitoring and control capabilities, PAT and information systems can provide detailed information on physical, chemical, and microbiological properties when multivariate methods are applied. $^{25-30}$ Typically, multivariate data analysis algorithms such as principal component analysis (PCA), partial leastsquares regression (PLSR), principal component regression (PCR), multiple linear regression (MLR), and variations of these methods are applied to build calibration models for process monitoring and closed-loop control. Multivariate methods when combined with population balance modeling can also be used to derive mathematical relationships between certain desired product properties, for example, CSD and 
contributing variables, such as concentration/supersaturation. ${ }^{25}$ Information provided by multivariate methods is also useful for process modeling and optimization. Some investigators have also explored univariate calibration-free approaches for process monitoring. A detailed discussion on calibration-free methods can be found in a recent review by Nagy et al. ${ }^{25}$ These methods often assume a linear dependency of signal intensity on the solute and/or solid concentration, and they cannot cope with interferences that result in noisy signals or temperature effects. The inherent advantage of multivariate statistical methods is the ability to reduce signal noise and select otherwise nonselective signals to improve calibration model development. ${ }^{31}$

\section{MATERIALS AND METHODS}

The continuous cooling crystallization of paracetamol (4acetamidophenol (PCM), 98\% purity purchased from SigmaAldrich UK) from isopropyl alcohol (propan-2-ol (IPA), analytical grade, $99.97 \%$ purchased from Fisher Scientific UK) was investigated with and without additives. The additive used in the study was HPMC (analytical grade, purchased from Sigma-Aldrich UK). Experiments were carried out using a modified MSMPR unit, as shown in Figure 1. A recirculation loop was incorporated in the design so that product slurry withdrawn from the MSMPR is sent to a dissolver, which also serves as a feed/recycle unit. ${ }^{1,32,33}$ Importantly, this arrangement allows the MSMPR to operate as a continuous, unseeded system for long periods, without using the large quantities of material often consumed by flow crystallizers. The added value of the modified MSMPR unit is that continuous crystallization of high-value active pharmaceutical ingredients (APIs) can be investigated using only a small amount of material, in particular, during the preclinical and phase I stages of drug development.

Figure $1 \mathrm{a}-\mathrm{c}$ shows a schematic layout with PAT tools, flow diagram, and photograph of the experimental setup used, respectively. The modified MSMPR consisted of a $750 \mathrm{~mL}$ crystallizer and $400 \mathrm{~mL}$ dissolver vessel, each with independent temperature controllers. The MSMPR was connected to the dissolver using Masterflex platinum cured silicon tubing (6.4 $\mathrm{mm}$ ID). A heat exchanger consisting of a jacketed $220 \mathrm{~mm}$ length glass tube with smooth periodic baffle constrictions ( 5 $\mathrm{mm}$ i.d. with $2.0 \mathrm{~mm}$ constrictions) connected to a thermofluid circulator bath was incorporated to cool the recycle sent back to the crystallizer and mitigate rapid fouling and encrustation following nucleation. The baffled heat exchanger has a high surface, which leads to rapid removal of heat from the incoming feed solution. It is an important modification to the MSMPR unit because it prevents a large temperature difference from developing when hot solution from the dissolver enters the crystallizer held at a much lower temperature to provide the driving force for crystallization.

Figure 2 shows the detrimental effect of fouling observed during preliminary development experiments with the closedloop MSMPR design, without the heat exchanger modification. Severe fouling and crust formation occurred on the PAT probes and vessel walls of the MSMPR crystallizer.

2.1. Automated Intelligent Decision Support System. A Kaiser RamanRxn instrument with 785 nm laser, fitted with RXN 1-784 immersion probe (iC Raman 4.1 software for data analysis and visualization), was used to obtain spectra for the development of a multivariate calibration model for solutionphase concentration measurements using Thermo Scientific TQ Analyst, version 8, chemometrics software package. The solution phase was also tracked using a Carl Zeiss MSC621
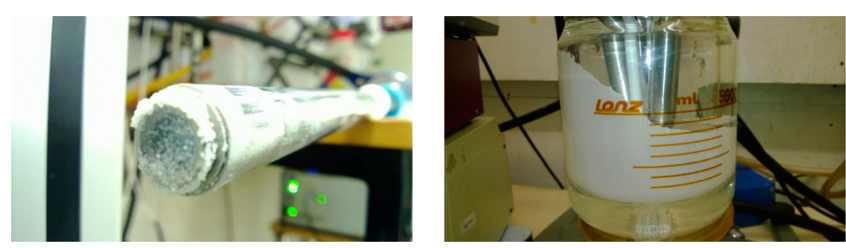

Figure 2. Fouling and crust formation on (left) PAT probe and (right) MSMPR vessel walls observed during the continuous crystallization of PCM using the closed-loop crystallizer design without heat exchanger.

ATR-UV/vis spectrometer fitted with a Helma ATR 661.822UV probe. The unit was coupled with an in-house-developed LabView software program. Lasentec's D600L FBRM unit with an immersion probe (used with Mettler Toledo FBRM software, version 6.7.0) and V819 PVM unit fitted with an immersion probe (used with Mettler Toledo PVM image acquisition software, version 8.3) were used to track the particle properties of the system. CryPRINS together with the integrated PAT array (ATR-UV/vis (with a multivariate calibration model) and FBRM) and ancillary PAT (in situ Raman (with a multivariate calibration model) and PVM) was used as an automated intelligent decision support (IDS) system. The IDS framework shown in Figure 3 was used to

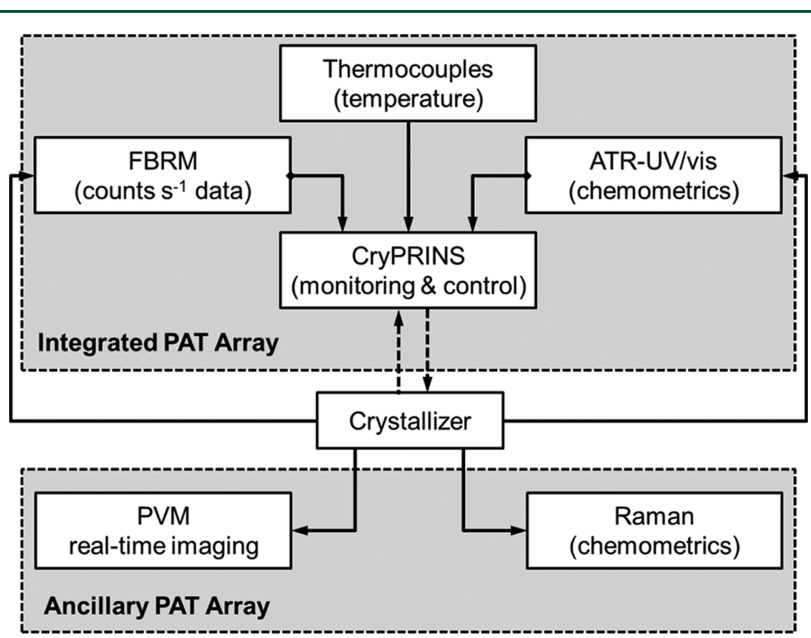

Figure 3. Automated intelligent decision support (IDS) system with integrated and ancillary PAT arrays and CryPRINS software used for connectivity to PAT tools, process monitoring, and temperature control.

control temperature, monitor solution concentration, track the particle size, and shape properties of the continuous crystallization process. The IDS is also able to detect any system deviations due to perturbations caused, for example, by transfer line blockages, flow rate changes and fouling, or impurity build-up. These effects are easily captured because of large temperature variations that occur from the process set point or, in the case of impurities, as changes in the Raman and ATR-UV/vis signals, respectively. The CryPRINS interface in the IDS provided connectivity to the integrated PAT array, and the display feature allowed for real-time monitoring of sensor signals and the determination of steady-state operation in the MSMPR. The interface also allows for the implementation of various control strategies to achieve a desired crystallization outcome, as demonstrated previously in batch crystallization studies by Saleemi et al. ${ }^{34}$ and Bakar et al. ${ }^{35}$ 
2.2. Continuous Crystallization Studies. The continuous unseeded cooling crystallization experiments were carried out in the single-stage MSMPR unit with recycle stream in a closed loop (Figure 1) using only a small amount of material. At startup, a suspension of $0.232 \mathrm{~g}$ PCM/g IPA in the MSMPR was heated at $65{ }^{\circ} \mathrm{C}$ and held for $15 \mathrm{~min}$ to allow complete dissolution of PCM. The resulting solution was then cooled to $45{ }^{\circ} \mathrm{C}$ while simultaneously heating a solution of pure IPA in the dissolver to the same temperature. Once both vessels reached $45{ }^{\circ} \mathrm{C}$, the solution in each was pumped continuously between them using Masterflex peristaltic pumps at a rate of 60 $\mathrm{g} / \mathrm{min}$ to homogenize the vessel contents. In effect, this created a closed-loop system, in which the final solution concentration was $0.152 \mathrm{~g} \mathrm{PCM} / \mathrm{g}$ IPA $\left(T_{\text {sat }}=35^{\circ} \mathrm{C}\right)$. Once the contents of the vessels were homogenized, as determined by real-time concentration measurement using multivariate calibration models developed with Raman and ATR-UV/vis (linked to CryPRINS) probes, ${ }^{34}$ solution from the dissolver/feed vessel was sent to the baffled tube heat exchanger, where it was cooled from 45 to $20{ }^{\circ} \mathrm{C}$ before entering the MSMPR crystallizer, which was controlled at $10{ }^{\circ} \mathrm{C}$. This start-up strategy led to generation of supersaturation required to drive primary nucleation and produce the initial start-up slurry while preventing rapid crust formation. The MSMPR was maintained at $10{ }^{\circ} \mathrm{C}$ and the dissolver was maintained at $45{ }^{\circ} \mathrm{C}$ for the duration of each experimental run (Figure 1b). The ATR-UV/ vis multivariate calibration model used for real-time concentration measurement and result display in CryPRINS was of the form

$$
c=b_{o}+b_{1} d+b_{2} T+b_{3} d T
$$

where $c$ is the concentration in (g PCM/g IPA), $T$ is the process temperature $\left({ }^{\circ} \mathrm{C}\right), b_{o}, b_{1}, b_{2}$, and $b_{3}$ are fitted regression coefficients with values of $-0.0290,-3.7889,-0.0002$, and -0.0248 , respectively, and $d$ is the first derivative of the absorbance at the selected wavelength $(266 \mathrm{~nm})$. The first derivative of the absorbance is used because it removes baseline offsets in the spectra. In addition, a simple nonlinear term expressed as the product of the derivative of the absorbance and temperature is included to improve the accuracy of the calibration model. Further details on the model development using ATR-UV/vis can be found in previous works. ${ }^{34,36}$

Continuous crystallization control experiments with no additive added were carried out using the experimental startup and operating procedures described earlier. Once the system was operational, slurry from the MSMPR outlet was continuously withdrawn and dissolved completely in the dissolver vessel, and the resulting solution was recycled back to the MSMPR. The flow rates employed are shown in Figure $1 \mathrm{~b}$ and resulted in mean residence times (RTs) of 12.12 and $6.38 \mathrm{~min}$ in the MSMPR and dissolver vessels, respectively. The duration of each experiment was approximately $4.6 \mathrm{~h}$ (inclusive of the start-up period). The process was operated for approximately $18 \mathrm{RT}$ s from the point of nucleation detection in the MSMPR.

Experiments with additive addition were carried out in a similar way to the experiments in which no additive was added (control experiments) using the MSMPR crystallizer setup shown in Figure 1. HPMC was added to the system to prevent fouling and encrustation over time and alleviate problems that were encountered during the initial development stages of the MSMPR (Figure 2). Three concentrations of HPMC were investigated, $0.001,0.003$, and 0.05 wt \% (expressed as a mass percentage of HPMC relative to the mass of PCM initially charged into the MSMPR). For each experiment, the required amount of HPMC was added to the MSMPR at the start of the $15 \mathrm{~min}$ homogenization period. For the experiment in which 0.05 wt \% HPMC was added, the dissolver temperature was elevated to $50{ }^{\circ} \mathrm{C}$. This was due to incomplete dissolution of small amounts of large crystals, as observed from visual inspection of material flowing through the recycle transfer line during preliminary experimental runs, in which the vessel was maintained at $45{ }^{\circ} \mathrm{C}$

2.3. Effect of HPMC on Raman and ATR/UV/Vis Signals. HPMC was found to have no effect on the Raman or ATR-UV/vis signals at all applied concentrations. Figure 4

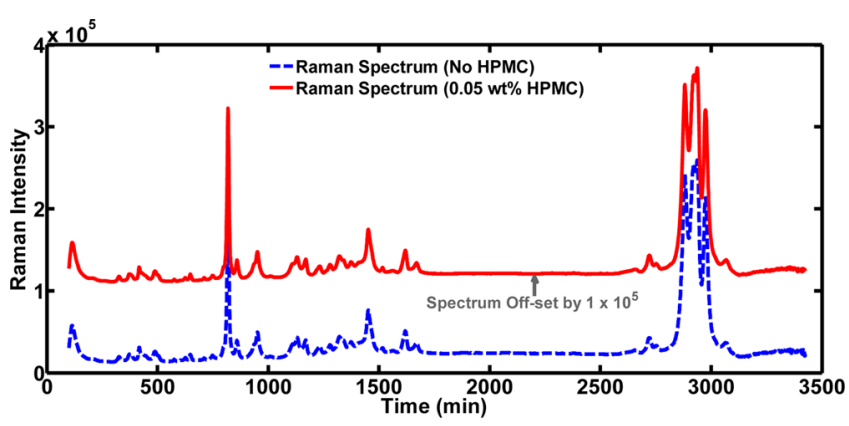

Figure 4. Raman spectra from solution phase for experiments carried out with 0.05 wt \% HPMC (straight line) and no HPMC (dashed line) addition at concentrations of 0.153 and $0.156 \mathrm{~g}$ PCM/g IPA, respectively.

shows the Raman spectra of experiments carried out with 0.05 wt \% HPMC and with no HMPC addition at similar PCM concentrations ( 0.153 and $0.156 \mathrm{~g} \mathrm{PCM} / \mathrm{g}$ IPA, respectively). There is no evidence of extra peaks or other spectral features (such as peak broadening or distortion) related to Raman scattering effects from HPMC. Therefore, the Raman signal of PCM can be taken to be independent of the HPMC concentration. Furthermore, signal changes due to the presence of interference can be minimized or eliminated by applying mathematical preprocessing techniques to the data. ${ }^{3}$

2.4. Raman Calibration Model for Solution Measurements. Raman spectra of PCM dissolved in IPA were collected using the Kaiser RamanRxn instrument with an RXN 1-784 probe. Spectra were collected in the range $3425-100 \mathrm{~cm}^{-1}$ at a spectral resolution of $4 \mathrm{~cm}^{-1}$. The number of scans and exposure time for each sample was $4.9 \times 7 \mathrm{~s}$ over a total measurement time of $60 \mathrm{~s}$. PCM-IPA solutions were prepared at saturation temperatures between 10 and $50{ }^{\circ} \mathrm{C}$. The saturation temperatures of PCM in IPA were estimated from solubility data published by Hojjati et al. ${ }^{38}$ These solubility data were also used by Saleemi et al. ${ }^{34}$ in a study on comparative batch crystallization control strategies using PCM-IPA as a model system. It is well-known that the presence of additives can lead to an increase in solubility of paracetamol, ${ }^{39-41}$ which subsequently leads to longer induction times ${ }^{41}$ and suppression of the nucleation rate. ${ }^{48,41}$ However, the degree to which HPMC affects the solubility of PCM is not known. Therefore, the solubility of PCM in this study is taken to be that of pure solutions. It is likely the effect of HPMC on PCM solubility is marginal given the very low concentrations applied in the study. The model equation used to determine the solubility of PCM (g PCM/g IPA) in IPA as a function of temperature $\left({ }^{\circ} \mathrm{C}\right)$ was 


$$
c(T)=2.742 \times 10^{-5} T^{2}+1.328 \times 10^{-3} T+7.202 \times 10^{-2}
$$

For the calibration model development and validation, Raman spectra were collected over a range of different temperatures (solid-free experiments) and in solid-liquid suspensions with different solid concentrations (solid-phase experiments), respectively. ATR-UV/vis and FBRM probes were used to detect dissolution and nucleation events. TQ Analyst software was used for Raman spectra pretreatment, model development, and concentration determination. In total, 2219 spectra were used for model development and validation. Of these, there were 2009 calibration standards, 150 solid-free validation standards, and 60 solid-liquid suspension validation standards. The standard normal variate (SNV), Savitzky-Golay (for derivatives and smoothing), and partial least-squares regression (PLSR) options in TQ Analyst were applied to build the calibration model. SNV compensates for differences in sample path lengths and minimizes the effects of particle scattering on the Raman signal. ${ }^{37,42}$ Savitzky-Golay firstderivative with seven-point smoothing was then applied, which provided robust background reduction by eliminating baseline shifts while emphasizing small spectral features relative to large ones. $^{37,43,44}$ PLSR was used to obtain the principal components (factors) for constructing the model. ${ }^{45,46}$ A total eight factors were applied, which allowed sufficient data to be used to correlate changes in the spectral and concentration data, respectively. The maximum error between the predicted and model determined concentration was $3.7 \%$. The root-meansquare error of prediction (RMSEP) ${ }^{47}$ between the validation and calibration data sets was $0.0074 \mathrm{~g} / \mathrm{g}$ (based on the lowest concentration measurement).

\section{RESULTS AND DISCUSSION}

3.1. Continuous Crystallization in the Absence of HPMC Additive. Several challenges were encountered during the development stages of the continuous crystallization apparatus: (1) particle settling and blockage of transfer lines, particularly near the peristaltic pump, (2) fouling and encrustation on the walls of the MSMPR and dip tube, and (3) fouling on PAT probes. These issues were mainly due to the narrow bore size of transfer lines ( $3 \mathrm{~mm}$ i.d.), the low flow rate requirement to achieve long residence times, leading to particle settling, and operation of the MSMPR with recirculation loop, which resulted in the creation of localized regions of high supersaturation, uncontrolled nucleation, and eventually fouling and encrustation. Similar issues were encountered by other investigators, ${ }^{9,10,48}$ but they were largely avoided here by using the modified MSMPR (Figure 1). However, fouling on the PAT probes and mild encrustation on the vessel walls persisted over prolonged operation. Figure 5 shows the process time diagram for the control experiment (no additive). The changes in concentration, temperature, and FBRM counts/s as well as the point of probe removal and cleaning due to fouling are shown. Periodic cleaning of the probes was necessary when fouling was detected to avoid the recording of erroneous results, a practice often not reported in the literature.

The crystallization proceeded without any washout issues, which is often reported in the literature. ${ }^{19}$ This is attributed to the start-up method employed that was described in Section 2.2. During the nucleation phase, there is a rapid increase in FBRM counts/s and the CSD changes dynamically, as indicated

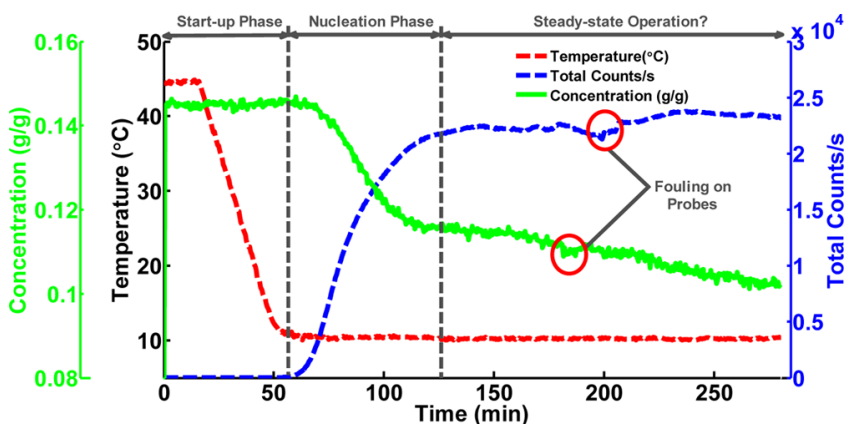

Figure 5. Time diagram showing temperature, FBRM counts/s, and Raman concentration measurements obtained from the MSMPR. The start-up phase is indicated as the initial period prior to nucleation. Points in the process where fouling was detected on the PAT probes are circled.

by the square-weighted chord length distribution (SWCLD) data shown in Figure 6a. After approximately $127 \mathrm{~min}$ (6th RT
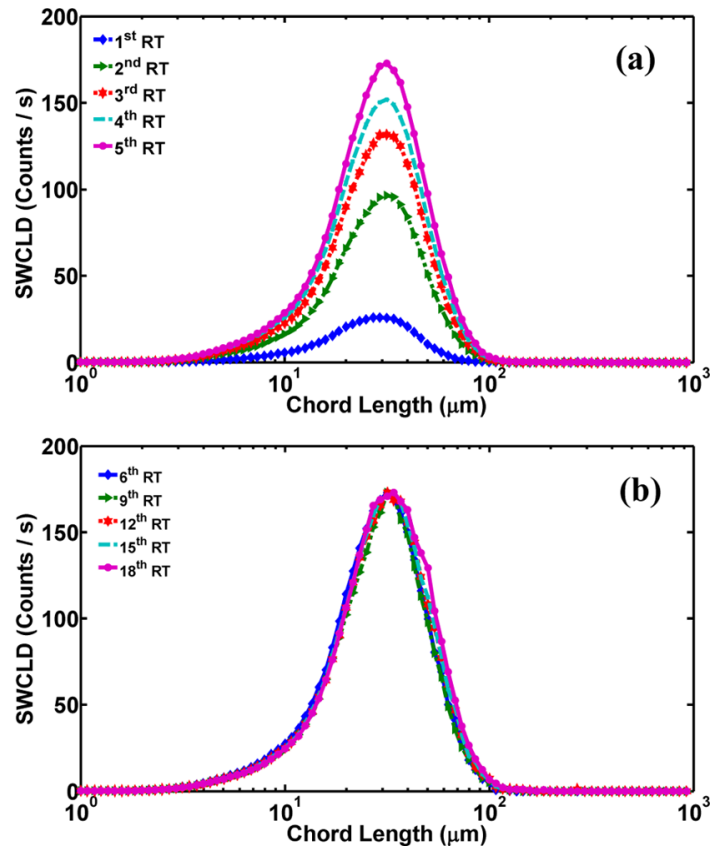

Figure 6. Evolution of FBRM square-weighted chord length distribution (SWCLD) from (a) the 1st to 5th RT, which indicates the dynamic state of change in the MSMPR, and (b) the 6th to 18th $\mathrm{RT}$, which indicates that the MSMPR is at steady state.

onward), the FBRM counts stabilize and the system arrives at a steady-state mean particle size and CSD. This is confirmed by overlapping of the SWCLD from the 6th to 18th RT onward, as shown in Figure $6 \mathrm{~b}$.

The Raman concentration data (Figure 5) paints a different picture of the process when compared to the FBRM total counts/s and SWCLD data. There is a decreasing trend from the onset of nucleation $(0.153 \mathrm{~g}$ PCM $/ \mathrm{g}$ IPA) to the end of the experiment (0.089 g PCM/g IPA). The ATR-UV/vis data also indicated that the concentration was decreasing over the period. Figure 7 shows the phase diagram of the process, showing the trajectory of concentration (measured by ATR-UV/vis) and temperature changes. At the point of intersection with the indicative metastable curve, nucleation is observed. The final recorded concentration of the process, indicated with a dot, is 


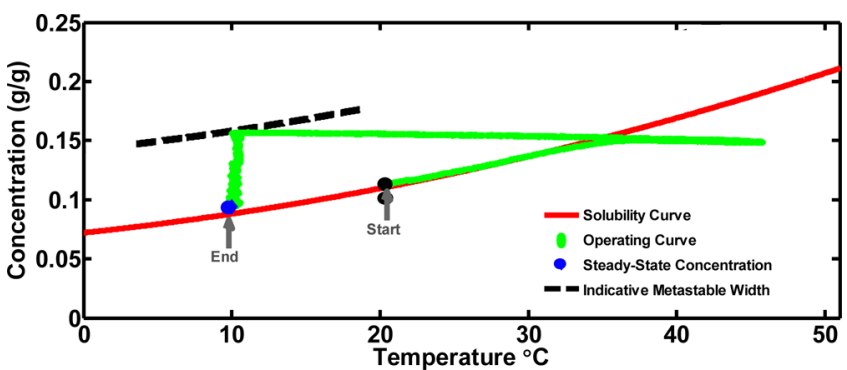

Figure 7. Phase diagram showing solubility and operating curves and indicative metastable width for PCM in IPA generate from ATR-UV/ vis calibration model in the CryPRINS interface. Initial (start) and final (end) recorded concentrations are indicated as dots on the phase diagram.

close to the solubility curve, indicating that the process is close to equilibrium. It appears that the FBRM probe is indicating steady-state behavior of the system due to particles sticking on to the surface (Figure 5). This is an important observation and suggests that relying on just a single PAT to monitor steadystate behavior can lead to erroneous results.

Raman and ATR-UV/vis with their respective multivariate calibration models gave similar concentration measurements. The concentration data from both methods indicated that the system was in a dynamic state of change and that steady state had not been attained. This is an important observation since many recent studies on the subject of continuous crystallization monitoring characterized steady state by relying solely on FBRM $^{9,18,32,49-51}$ and/or imaging techniques (for example, low angle light scattering (LALLS) and PVM ${ }^{19,51}$ ) or calibrationfree spectroscopy approaches. 9 Arguably, real-time determination of concentration using multivariate models supported by online particle measurements provides a more robust measure of steady-state operation, as opposed to just tracking changes in FBRM statistics or using calibration-free methods. Since these are essentially qualitative measures, they may not reliably determine the attainment of steady-state operation. In some studies, offline concentration measurements ${ }^{50,52,53}$ or gravimetric mass balance analysis and/or offline particle size analysis $^{2,48,54}$ are used to determine steady-state operation. These methods are not only laborious but also prone to error due to the amount of sample handing involved. Furthermore, losses often occur during the sample filtration step. The use of PAT with multivariate models, as demonstrated here, provides a robust approach for characterizing the continuous MSMPR process in addition to using FBRM, and PVM technologies. Potentially, other image analysis techniques such as bulk video imaging (BVI) $)^{55,56}$ or endoscopy-stroboscopy ${ }^{57}$ in concert with multivariate image analysis methods could replace PVM to provide more useful information for further process characterization, in particular, of nucleation and growth phenomena. The advantages of multivariate methods are well-documented for batch processes; ${ }^{23,38,58}$ however, there remains limited application in continuous crystallization.

3.2. Continuous Crystallization Studies with HPMC Additive. Although many of the challenges encountered during the development stages of the MSMPR were alleviated by employing the modified configuration (Figure 1), problems persisted with fouling and mild encrustation in the MSMPR (Section 3.1). The use of HPMC additive was therefore explored as a means of eliminating these problems. HPMC is on the FDA list of substances generally regarded as safe
(GRAS). In a study on the effect of different polymers on the crystallization of PCM from aqueous solutions, Wen et al. ${ }^{59}$ showed that HPMC inhibited primary nucleation, perhaps via interactions with molecules in the bulk solution. They also found that growth and secondary nucleation were inhibited to a significant degree due to the adsorption of HPMC on to the (010) face of monoclinic form I crystals. It was thought that HPMC developed hydrogen-bonding interactions with PCM crystals in the direction of the $a$ axis on the (010) face, thereby disrupting the surface diffusion of PCM molecules in this direction and changing the etching patterns on the crystal surface. HPMC was therefore seen as a variable additive to use for controlling PCM crystallization, thereby preventing fouling and encrustation in the MSMPR. Figure 8 shows the process

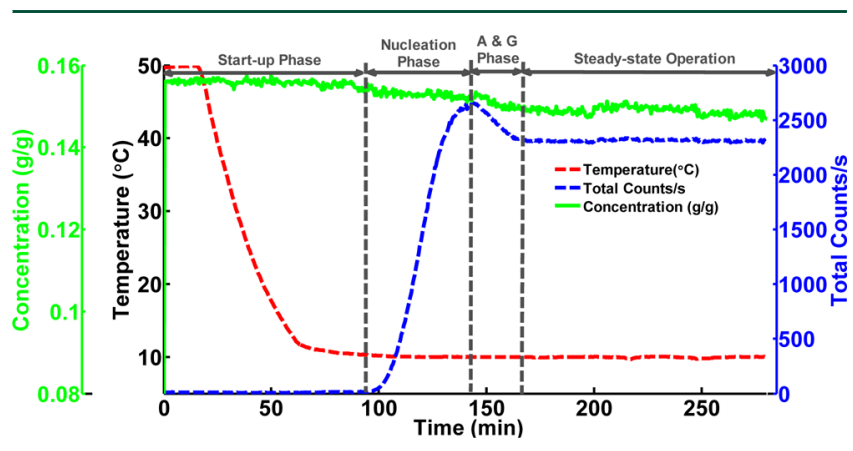

Figure 8. Time diagram showing real-time temperature, FBRM counts, and Raman concentration measurements obtained from the MSMPR with addition of $0.05 \%$ HPMC.

time diagram for the $0.05 \%$ HPMC continuous crystallization experiment. The start-up phase was extended due to the presence of HPMC, when compared to that of the control experiment (Section 3.1). Following this is the nucleation phase where the FBRM counts/s increase rapidly with simultaneous depletion of concentration. The maximum FBRM counts/s attained in the nucleation phase was about 2660 counts/s, which is almost an order of magnitude lower compared to the maximum value of 23800 counts/s recorded during the control experiment. This data indicates that HPMC not only delays the onset of nucleation in the system but also suppresses it significantly. These observations corroborate findings from previous studies ${ }^{21,59,60}$ on HPMC suppression of PCM nucleation. The "A and G phase", as show in Figure 8, refers to a period when there is both agglomeration (A) and/or growth (G) taking place, indicated by a decrease in FBRM counts/s and corresponding decrease in concentration. Following the $A$ and $G$ phase, the system achieves steady state whereby the FBRM counts and solute concentration are stabilized and remain constant for the duration of the experiment. Agglomeration was not detected in the no additive experiment (Figure 5); however, due to the extent of fouling on the FBRM probe in that experiment, it is not entirely clear if it occurred or not based on the total counts/s data. However, PVM and microscope images confirmed that there was significant agglomeration in that experiment.

Compared to the control experiment with no additive added (Figure 5), the change in concentration from the onset of nucleation in the MSMPR is small, further indicating that nucleation is being suppressed. The concentration decreases gradually from start-up from the level of 0.156 to $0.150 \mathrm{~g}$ $\mathrm{PCM} / \mathrm{g}$ IPA after $154 \mathrm{~min}$. The steady-state concentration (0.147 g PCM/g IPA) was reached after approximately $170 \mathrm{~min}$ 
and was maintained at that level until the end of the experiment. The FBRM SWCLD also confirmed steady-state operation was attained, as shown in Figure 9a,b (1st to 15th
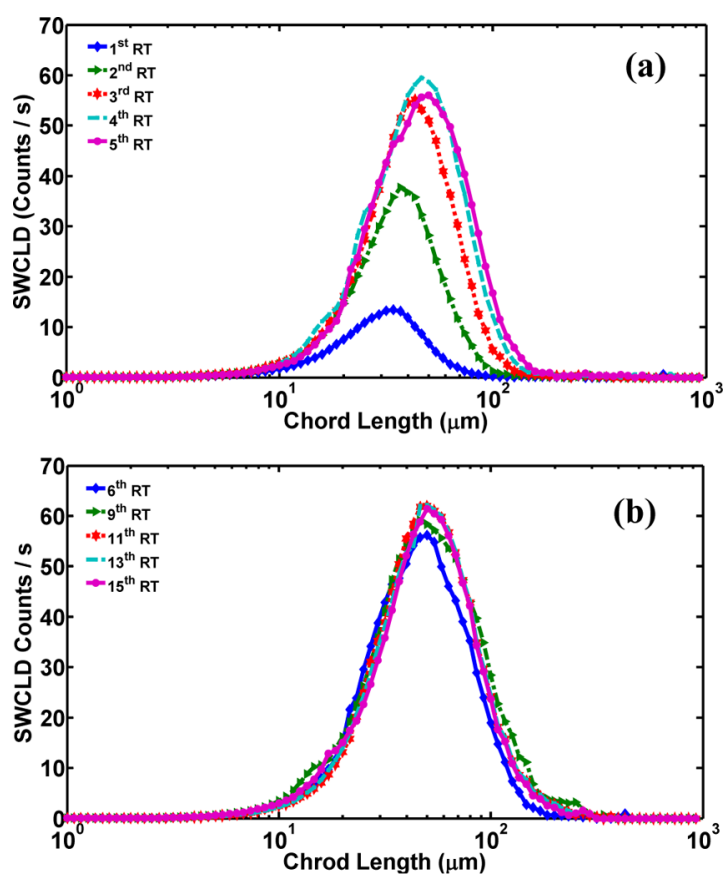

Figure 9. Evolution of FBRM square-weighted chord length distribution (SWCLD) from (a) the 1st to 5th RT, which indicates the dynamic state of change in the MSMPR, and (b) the 6th to 15th RT.

RT). The significant overlap of the distributions between the 6th and 15th RT, when combined with knowledge of the solute concentration from Raman measurements, confirms that the system is operating at steady state.

Figure 10 shows the phase diagram of the process, which indicates the region of steady-state operation. Compared to the

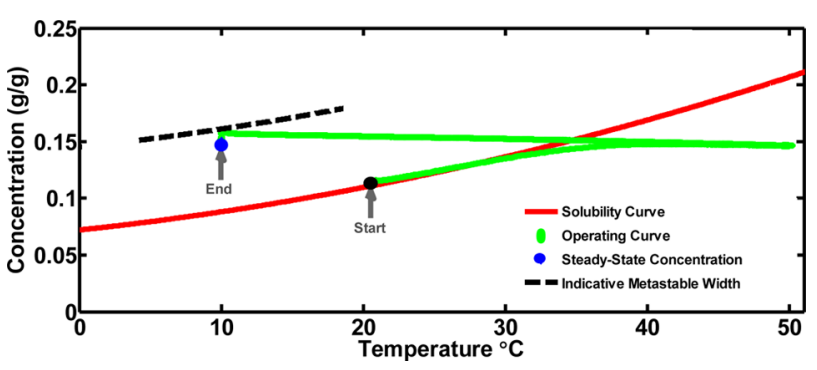

Figure 10. Phase diagram showing solubility, metastable, and operating curves for PCM in IPA generated using the ATR-UV/vis model in the CryPRINS interface. The operating curve indicates the trajectory through the phase diagram as the experiment progresses. Initial (start) and final (end) recorded concentrations are indicated by dots on the phase diagram.

control experiment, the steady state and hence the level of supersaturation is quite high, confirming the effect of HPMC on growth and nucleation suppression. ${ }^{21,59}$ Furthermore, there was a dramatic reduction in the process yield compared to the no additive experiment. Due to the dramatic effect of $0.05 \mathrm{wt} \%$ HPMC on the delay and suppression of PCM nucleation and growth rate, further investigations were conducted at lower concentrations (0.001 and 0.003 wt \%). Table 1 gives a summary of the results from this set of experiments, as well as those reported in earlier sections of this article. The supersaturation $(S)$ as reported is defined as $c_{i} / c^{*}$. The data shows that there is a direct correlation between HPMC concentration in the system and induction time. Conversely, and as expected, there is an inverse correlation between HPMC concentration and FBRM counts/s data and fractional yield of crystallization.

The fractional yield $(Y)$ represents the amount of product obtained from the crystallization process relative to the amount of available supersaturation and is calculated from

$$
Y=\frac{c_{o}-c_{i}}{c_{o}-c_{i}^{*}} \times 100
$$

where $c_{o}, c_{i}$, and $c^{*}$ are the dissolver/feed stream concentration (g PCM/g IPA), MSMPR steady-state concentration, and equilibrium concentration at the specified operating temperature, respectively. The data presented in Table 1 shows there is a direct correlation between the HPMC concentration and the level of supersaturation at which the MSMPR operates. Steady state was not observed for either the 0.001 or $0.003 \mathrm{wt}$ $\%$ HPMC additive experiments due to the persistence of fouling and encrustation problems.

It appears from the results presented in Table 1 that HPMC is suppressing both the nucleation kinetics and growth kinetics (to a lesser extent) of PCM. There is a clear decrease in particles with increasing HPMC concentration, which indicates a suppression of nucleation. The FBRM mean-square-weighted chord length (MSWCL) shows only marginal changes in size with increasing HPMC concentration.

3.3. Characterization of Crystal Properties from FBRM Statistics and Image Analysis. The crystal properties from the continuous MSMPR crystallization were investigated further using FBRM statistical trends, real-time PVM, and offline microscope image analysis. Figure $11 \mathrm{a}-\mathrm{d}$ provides a comparison between the FBRM statistical trends for the control and $0.05 \%$ HPMC additive experiments. These time diagrams show the fraction of total counts/s for each size range. In the early stages of each experiment, just following the onset of nucleation, the $1-5$ and $6-25 \mu \mathrm{m}$ size fractions accounted for greater than $90 \%$ of the total counts/s. However, as growth becomes the dominant crystallization mechanism, a large reduction in the smaller size fractions for the 0.05\% HPMC experiment is observed. This compares to a much smaller reduction in the amount of fine crystals for the control experiment.

The contribution of each size fraction to the CSD as the system approaches steady-state operation provides further evidence of the effect of HPMC on the suppression of nucleation and subsequent growth of crystals. Figure $11 \mathrm{a}$ further indicates that the $1-5 \mu \mathrm{m}$ size fraction contributes only a small amount (approximately 13.1\%) to the total counts/s for the 0.05 wt \% HPMC experiment. This compares to a much larger contribution (approximately 31.3\%) to the total counts/s from crystals in the same size range for the control experiment. The $6-25 \mu \mathrm{m}$ fraction contribution to the total counts/s for the control and 0.5 wt \% HPMC additive experiments were similar (approximately 55 and 50\%, respectively). The 27-50 and 54-100 $\mu \mathrm{m}$ fractions combined contributed approximately $35.3 \%$ to the steady-state total counts/s for the 0.05 wt $\%$ HPMC experiment, whereas the contribution was only $13.7 \%$ for the control experiment. These results indicate that while 
Table 1. Summary of Experimental Results Showing the Effect of HPMC Additive on the Continuous Cooling Crystallization of PCM

\begin{tabular}{lccccc}
$\begin{array}{c}\text { HPMC } \\
(\mathrm{wt} \%)\end{array}$ & $\begin{array}{c}\text { induction time: from the onset of } \\
\text { cooling (min.) }\end{array}$ & $\begin{array}{c}\text { nucleation phase max. FBRM } \\
(\text { counts/s) }\end{array}$ & $\begin{array}{c}\text { FBRM MSWCL } \\
(\mu \mathrm{m})\end{array}$ & $\begin{array}{c}\text { fractional yield of } \\
\text { crystallization }(\%)\end{array}$ & $\begin{array}{c}\text { supersaturation } \\
\left(c_{i} / c^{*}\right)\end{array}$ \\
\hline 0 & 58 & 23800 & 35.2 & 98.8 & 1.015 \\
0.001 & 59 & 15119 & 61.0 & 56.6 & 1.314 \\
0.003 & 64 & 7146 & 63.5 & 40.7 & 1.536 \\
0.050 & 97 & 2656 & 60.6 & 28.0 & 1.665
\end{tabular}
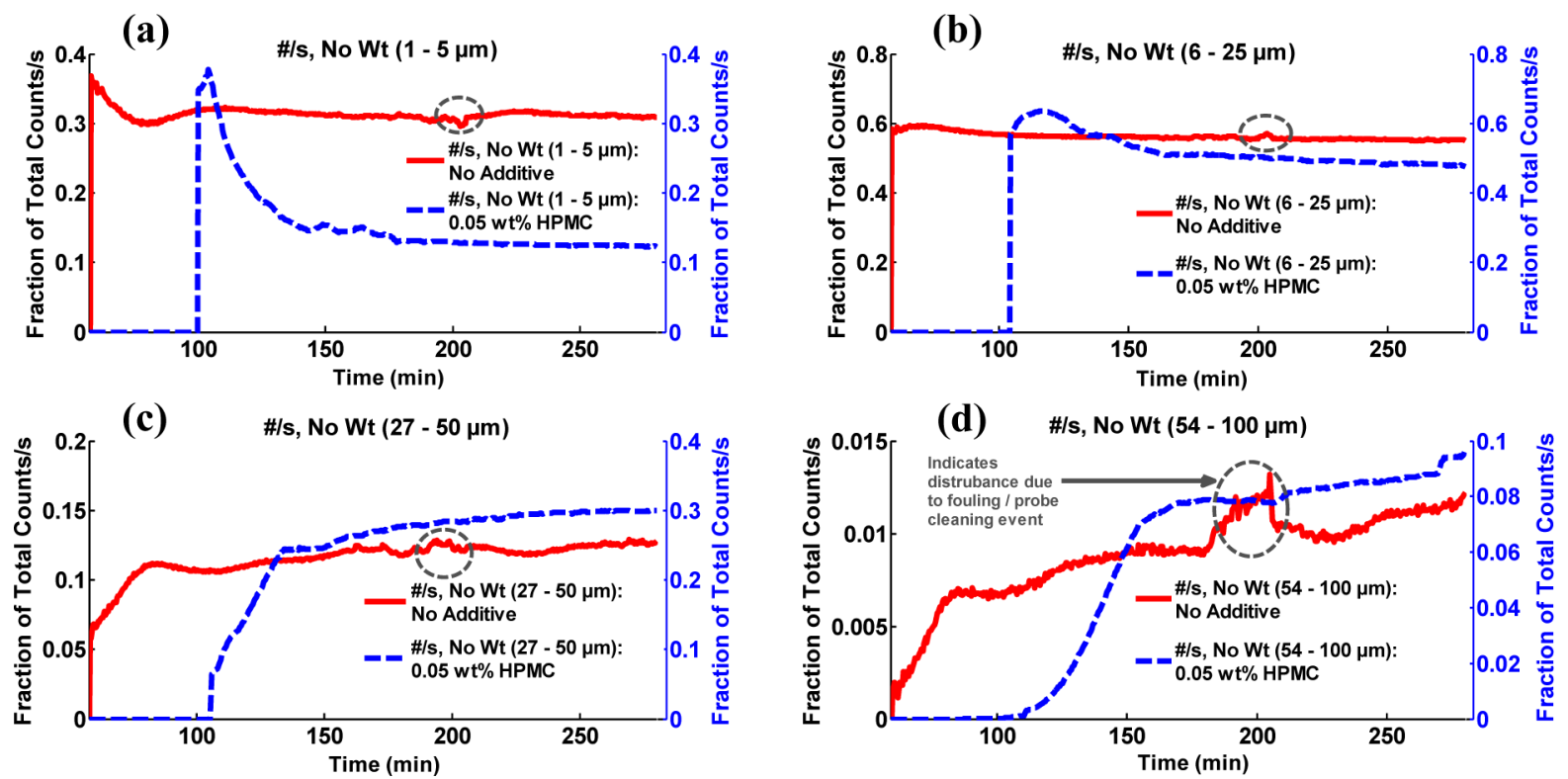

Figure 11. Real-time FBRM statistical data showing the fraction of particle counts/s for a range of size fractions for the MSMPR control (no additive) and $0.05 \mathrm{wt} \%$ HPMC experiments: (a) no weighted counts/s 1-5 $\mu \mathrm{m}$, (b) no weighted counts/s 6-25 $\mu \mathrm{m}$, (c) no weighted counts/s $27-$ $50 \mu \mathrm{m}$, and (d) no weighted counts/s 54-100 $\mu \mathrm{m}$.

HPMC is suppressing nucleation to a significant degree, much larger product crystals are obtained compared to the control experiment. It is likely that due to the severe suppression of nucleation the few crystals present in the system have less competition for solute molecules and thus can grow larger. However, it is likely that the rate of growth of these crystals is suppressed. Therefore, the overall deduction is that HPMC suppresses the nucleation as well as growth kinetics of PCM. Femi-Oyewo and Spring ${ }^{21}$ studied the effect of HPMC and other additives on PCM crystallization from aqueous solutions and reported a high degree of nucleation and crystal growth inhibition. In this study, microcrystals with low yield were observed. The investigators reported crystal size reduction from $4.28 \mathrm{~mm}$ (length) without HPMC addition (control) to between 0.3 and $0.42 \mathrm{~mm}$ (length) when HPMC additive in the concentration range $0.1-0.7 \mathrm{wt} \%$ was used. In these previous studies, the effect of HPMC on the product crystal size is rather dramatic compared to the results reported here. However, this is not surprising given the much higher concentrations that were employed in aqueous solution. Trends of the FBRM mean-square-weighted chord length (MSWCL) statistic shown in Figure 12 provide further evidence that larger product crystals are obtained from the 0.05 wt \% HPMC experiment compared to those from the control experiment. The mean size of crystals at the end of the control experiment was $35.2 \mu \mathrm{m}$. This compares to a mean steady-state crystal size of $60.6 \mu \mathrm{m}$ for the 0.05 wt \% HPMC experiment.

Real-time PVM images also indicate that there are larger crystals for the $0.05 \mathrm{wt} \%$ HPMC experiment relative to the

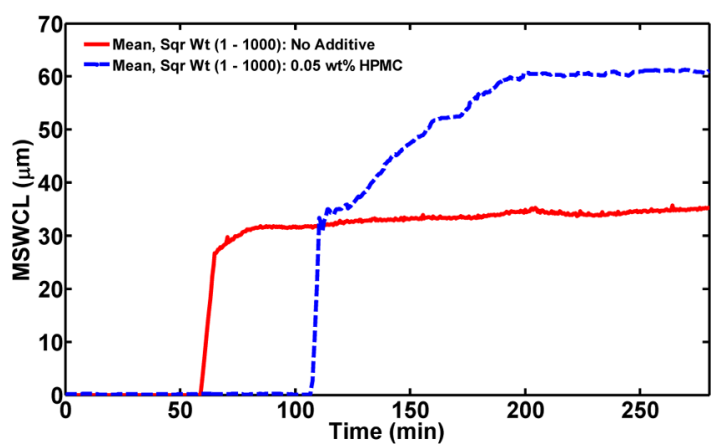

Figure 12. Real-time FBRM mean-square-weighted chord length (MSWCL) trends for the 0.05 wt \% HPMC and control (no additive) experiments.

control experiment. Figure 13a shows the change in appearance of crystals from the onset of nucleation (approximately $58 \mathrm{~min}$ ) to the end of the control experiment. There is a rapid increase in the number of crystals up to $130 \mathrm{~min}$, after which the PVM probe has become saturated due to the high particle density. On the other hand, Figure 13b shows the change in crystal properties captured by PVM from the onset of nucleation (approximately $97 \mathrm{~min}$ ) to the end of the $0.05 \mathrm{wt} \% \mathrm{HPMC}$ experiment. These crystals are clearly larger than those from the control experiment. PVM also indicates that steady state was achieved from 170 min onward since the crystals are of similar size and shape. 

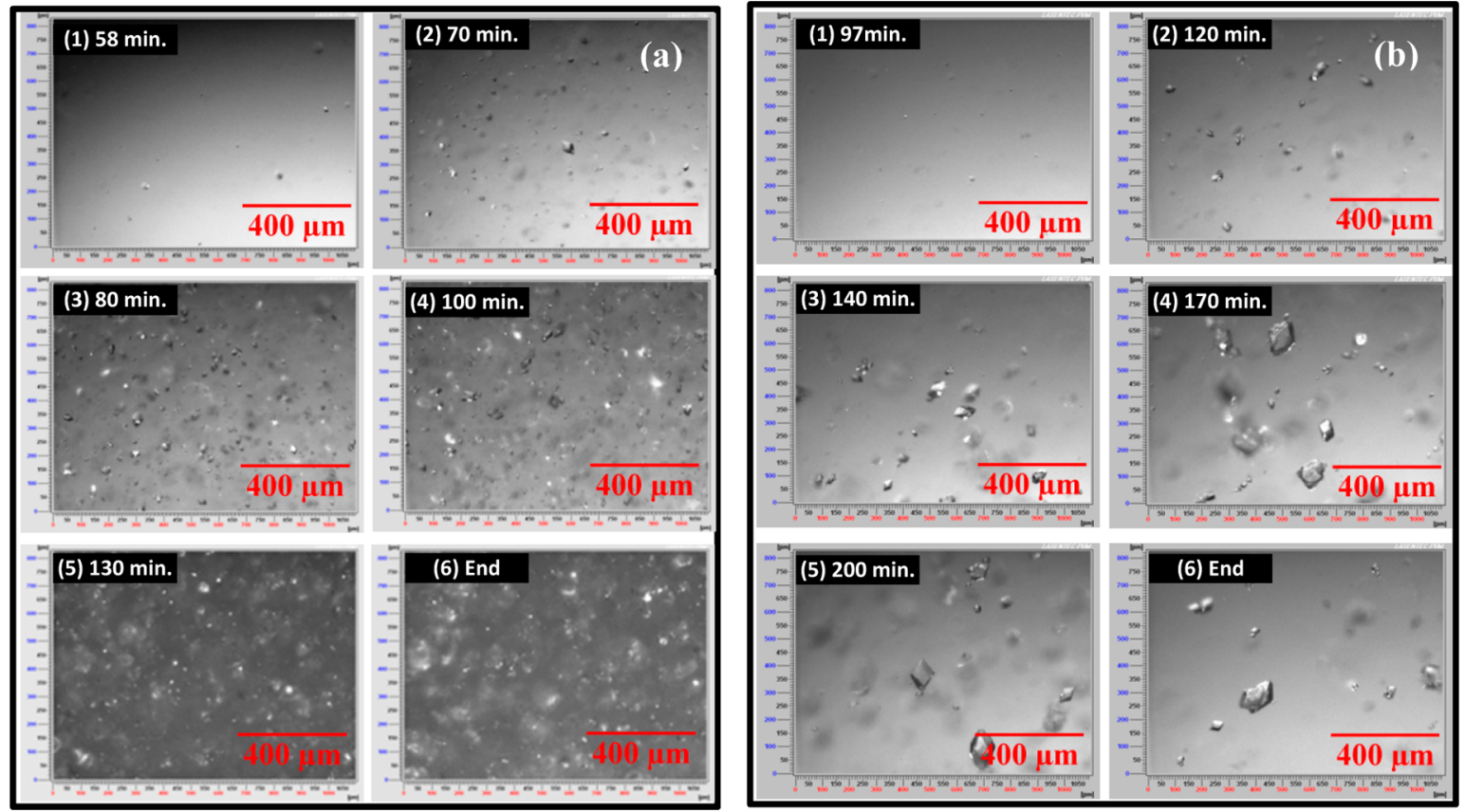

Figure 13. Real-time PVM images captured during (a) the control experiment (no additive) (due to the high particle density after 130 min, it is difficult to identify individual crystals) and (b) the $0.05 \mathrm{wt} \%$ HPMC additive experiment.
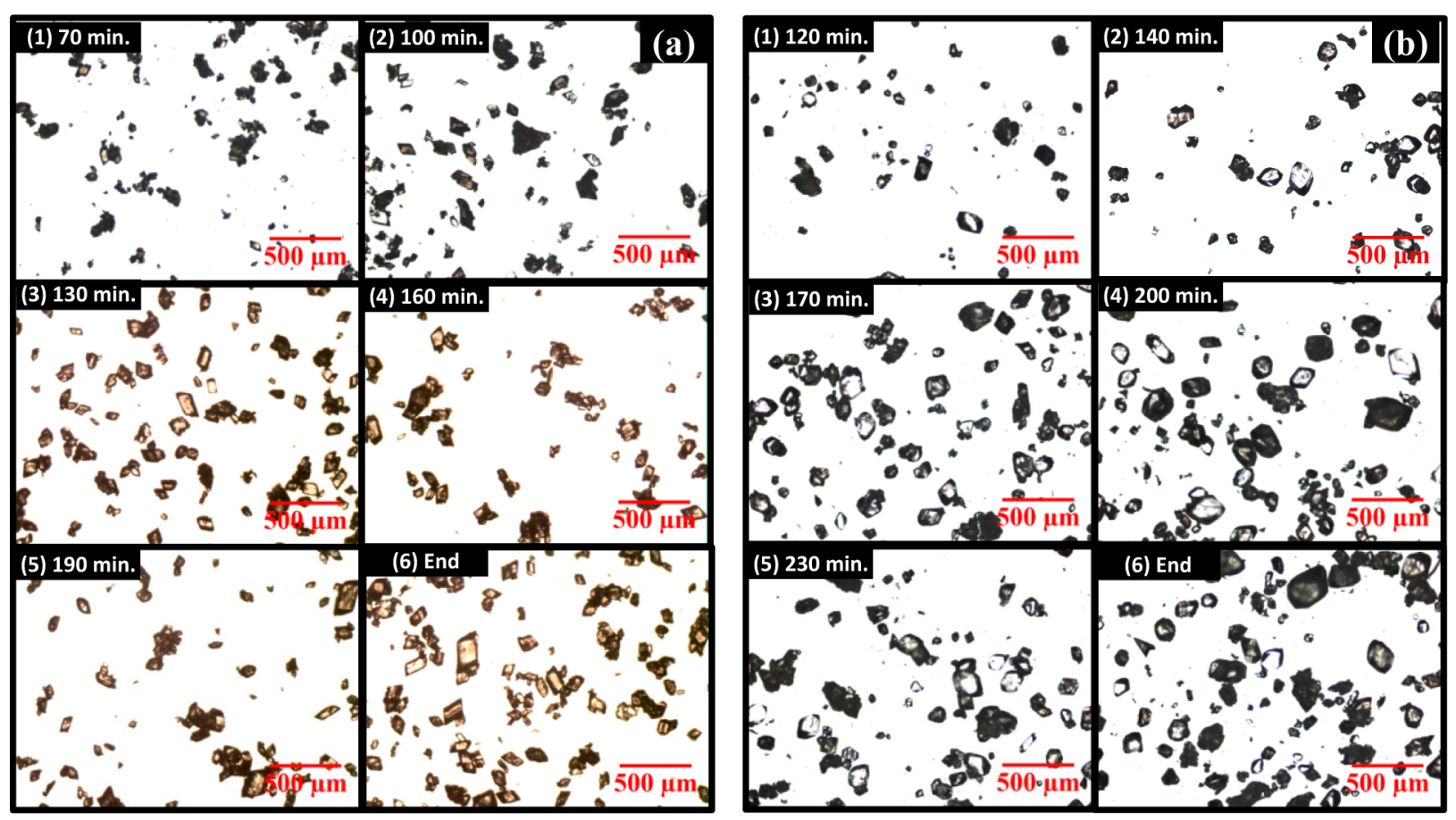

Figure 14. Offline microscope images of samples taken from the continuous crystallization experiments: (a) control experiment and (b) 0.05 wt $\%$ HPMC.

Offline microscope images also confirmed the differences in crystal size between the control experiment and the 0.05 wt \% HPMC experiment. Figure 14 shows the microscope images of samples taken from the control experiment. The images from $70 \mathrm{~min}$ to the end of the experiment show a gradual increase in the crystal sizes. Agglomerated, twinned, and single crystals can also be observed. PCM also exhibits several crystal habits with predominantly prismatic, tabular, and cuboid shaped crystals present. Ristic et al. ${ }^{61}$ examined the morphology of form I PCM crystals grown from aqueous solutions and concluded that the habit changes of PCM were due principally to changes in the growth mechanism of the (110) and (001) faces, which exhibit markedly different growth rates at high and low supersaturations. Crystal growth was found to be dominant on the (110) face at low supersaturations, which gave way to increasing dominance of the $(001)$ as the supersaturation increased. At low supersaturations $(<10 \%)$, crystals exhibiting a columnar or prismatic morphology elongated along the (001) axis, whereas at high supersaturations ( $>15 \%)$, crystals of a tabular morphology were reported. Wen et al. ${ }^{59,62}$ later showed 
that the mechanism of HPMC effect on PCM morphology was via hydrogen-bonding interactions. It is likely that HPMC interacts differently with PCM on the different crystal faces at high and low supersaturations, leading to the crystal morphological changes reported in this study. While these are interesting observations, investigation of those phenomena related to the crystal habit of PCM in the presence of HPMC was outside the scope of the study.

Figure 14a,b shows the microscope images of samples taken from the control experiment and the 0.05 wt \% HPMC experiment, respectively. Comparatively, the crystals obtained from the latter are significantly larger than those from the control run. It is also evident that the crystals are predominantly of a tabular habit with smoother edges, an indication that HPMC may be affecting the growth rate to a different degree on each crystal face. The effect of additives on crystal growth and morphology is well-documented in the literature. $^{39,63,64}$ Thompson et al. ${ }^{39}$ investigated the effect of structurally related additives on different crystal faces of form I PCM. They found that the growth of the (001) face, and hence the crystal morphology, was affected to different extents by acetanilide and metacetamol additives due to different interactions with the $\mathrm{NHCOCH}_{3}$ and $\mathrm{OH}$ functional groups, respectively. The microscope images (Figure 14a,b) indicate, qualitatively, the effect HPMC additive on growth of PCM crystals in the continuous MSMPR crystallizer. It may be that, at the applied concentration of HPMC, surface interactions that lead to suppression of growth on specific crystal faces occurs, leading to a subsequent change in the crystal habit.

\section{CONCLUSIONS}

In this study, a modified MSMPR crystallizer configuration that included a dissolver/feed unit, in-line heat exchanger, and recirculation loop was employed for the continuous cooling crystallization of PCM. In this closed-loop operation, slurry is continuously dissolved and recycled/fed back to the MSMPR, leading to continuous operation with minimal use of materials. The heat exchanger was able to minimize, but not completely eliminate, fouling and encrustation at start-up by reducing the temperature difference between the recycled solution and the contents of the MSMPR, leading to prolonged operation. Furthermore, start-up of the MSMPR was achieved without any wash-out issues, as are often reported in the literature.,19 Wash-out was avoided due to the start-up strategy employed, whereby material is circulated between the dissolver and MSMPR until nucleation is detected, as opposed to starting up with a suspension already in the MSMPR. ${ }^{19,51}$

Experiments were carried out with HPMC additive addition to further alleviate fouling and encrustation problems encountered during prolonged operation. More stable operation of the MSMPR was observed in the presence of HPMC additive, and steady state was achieved more readily when compared to that of a control experiment. However, HPMC shows a significant effect on the suppression of PCM nucleation and crystal growth (to a lesser extent). In the presence of HPMC, the product crystals obtained were tabular shaped and of similar size. For the control experiment in which no HPMC was added, predominantly fine crystals with a range of different morphologies were obtained. Direct correlations were observed among the HPMC concentration, induction time, and MSMPR steady-state supersaturation, whereas inverse relationship were found among HPMC concentration, the fractional yield, and number of particles detected. The combined results indicate that HPMC is an effective additive for alleviating fouling and encrustation. However, the penalty or cost is a significant suppression of nucleation (and growth to a lesser extent), which then leads to a low yield of crystallization.

The application of an IDS framework with integrated and ancillary PAT array and informatics software CryPRINS tool were used to monitoring the MSMPR operation. Robust multivariate models were applied using Raman and ATR-UV/ vis spectroscopy for solution concentration measurement. Furthermore, Raman spectroscopy is rarely used in crystallization to monitor solution-phase concentration. The results further indicate that the combined use of PAT tools within the IDS framework is essential to measure unambiguously the state of a crystallization and to determine when steady state is achieved. The PAT array provides a more robust approach for characterization of steady state compared to the use of standalone PAT monitoring frameworks or calibration-free approaches.

\section{AUTHOR INFORMATION}

\section{Corresponding Authors}

*(K.A.P.) E-mail: k.powell@lboro.ac.uk.

*(Z.K.N.) E-mail: zknagy@purdue.edu.

\section{Notes}

The authors declare no competing financial interest.

\section{ACKNOWLEDGMENTS}

The authors would like to thank the EPSRC (EP/I033459/1) and the Centre for Continuous Innovation in Continuous Manufacturing and Crystallization (CMAC) for the financial support of this work and the European Research Council under the European Union's Seventh Framework Program (FP7/ 2007-2013)/ERC grant agreement no. [280106-CrySys] (for equipment and financial support). Special thanks to Rajesh Gurang for creating the TOC artwork.

\section{ABBREVIATIONS}

IDS, intelligent decision support; PCM, paracetamol; IPA, isopropyl alcohol; HPMC, hydroxyl propyl methyl cellulose; MSMPR, mixed suspension mixed product removal; PAT, process analytical technology; CQA, critical quality attributes; CSD, crystal size distribution; ATR-UV/vis, attenuated total reflectance ultraviolet/visible spectroscopy; FBRM, focused beam reflectance measurement; CryPRINS, crystallization process informatics system; PVM, particle vision microscopy; NIR, near-infrared spectroscopy; ATR-FTIR, attenuated total reflectance Fourier transform infrared spectroscopy; PCA, principal component analysis; PLSR, partial least-squares regression; PCR, principal component regression; MLR, multiple linear regression; SNV, standard normal variate; RMSEP, root-mean-square error of prediction; RT, residence time; SWCLD, square-weighted chord length distribution

\section{REFERENCES}

(1) Kougoulos, E.; Jones, A. G.; Jennings, K. H.; Wood-Kaczmar, M. W. J. Cryst. Growth 2005, 273, 529-534.

(2) Narducci, O.; Jones, A. G.; Kougoulos, E. Chem. Eng. Sci. 2011, 66, 1069-1076.

(3) Ferguson, S.; Morris, G.; Hao, H.; Barrett, M.; Glennon, B. Chem. Eng. Sci. 2013, 104, 44-54.

(4) Simon, L. L.; Myerson, A. S. Associazione Italiana Di Ingegneria Chimica (AIDIC) 2011, 3-6. 
(5) De Beer, T.; Burggraeve, a; Fonteyne, M.; Saerens, L.; Remon, J. P.; Vervaet, C. Int. J. Pharm. 2011, 417, 32-47.

(6) Simon, L. L.; Pataki, H.; Marosi, G.; Meemken, F.; Hungerbühler, K.; Baiker, A.; Tummala, S.; Glennon, B.; Kuentz, M.; Steele, G.; Kramer, H. J. M.; Rydzak, J. W.; Chen, Z.; Morris, J.; Kjell, F.; Singh, R.; Gani, R.; Gernaey, K. V.; Louhi-Kultanen, M.; O’Reilly, J.; Sandler, N.; Antikainen, O.; Yliruusi, J.; Frohberg, P.; Ulrich, J.; Braatz, R. D.; Leyssens, T.; von Stosch, M.; Oliveira, R.; Tan, R. B. H.; Wu, H.; Khan, M.; O'Grady, D.; Pandey, A.; Westra, R.; Delle-Case, E.; Pape, D.; Angelosante, D.; Maret, Y.; Steiger, O.; Lenner, M.; AbbouOucherif, K.; Nagy, Z. K.; Litster, J. D.; Kamaraju, V. K.; Chiu, M.-S. Org. Process Res. Dev. 2015, 19, 3-62.

(7) Zarkadas, D. M.; Sirkar, K. K. Chem. Eng. Sci. 2006, 61, 50305048 .

(8) Westhoff, G. M.; Kramer, H. J. M.; Jansens, P. J.; Grievink, J. Chem. Eng. Res. Des. 2004, 82, 865-880.

(9) Ferguson, S.; Morris, G.; Hao, H.; Barrett, M.; Glennon, B. Chem. Eng. Sci. 2013, 104, 44-54.

(10) Whelan, R.; Barrett, M.; Hao, H.; Glennon, B. In 11th International Conference on Chemical \& Process Engineering, Milan, 2013; pp 1-4.

(11) Kougoulos, E.; Jones, A. G. Org. Process Res. Dev. 2006, 10, 125132.

(12) Eder, R. J. P.; Radl, S.; Schmitt, E.; Innerhofer, S.; Maier, M.; Gruber-Woelfler, H.; Khinast, J. G. Cryst. Growth Des. 2010, 10, 22472257.

(13) Eder, R. J. P.; Schmitt, E. K.; Grill, J.; Radl, S.; Gruber-Woelfler, H.; Khinast, J. G. Cryst. Res. Technol. 2011, 46, 227-237.

(14) Jasch, K.; Barth, N.; Fehr, S.; Bunjes, H.; Augustin, W.; Scholl, S. Chem. Eng. Technol. 2009, 32, 1806-1814.

(15) Randolph, A. D.; Larson, M. A. Theory of Particulate Processes; Academic Press: New York, 1971.

(16) Mullin, J. W. Crystallization, 4th ed.; Butterworth-Heinemann: Oxford, 2001.

(17) Mersmann, A. Crystallization Technology Handbook, 2nd ed.; Mersmann, A., Ed.; Marcel Dekker, Inc.: New York, 1995.

(18) Power, G.; Hou, G.; Kamaraju, V. K.; Morris, G.; Zhao, Y.; Glennon, B. Chem. Eng. Sci. 2015, 133, 125-139.

(19) Hou, G.; Glennon, B.; Morris, G.; Barrett, M.; Zhao, Y.; Power, G. In AIChE 12th Annual Meeting, Pittsburg, PA, 2012.

(20) Powell, K. A.; Saleemi, A. N.; Rielly, C. D.; Nagy, Z. K. Chem. Eng. Process. 2015, 97, 195-212.

(21) Femi-Oyewo, M. N.; Spring, M. S. Int. J. Pharm. 1994, 112, 1728.

(22) Saleemi, A.; Rielly, C. D.; Nagy, Z. K. CrystEngComm 2012, 14, 2196-2203.

(23) Saleemi, A. N.; Rielly, C. D.; Nagy, Z. K. Chem. Eng. Sci. 2012, $77,122-129$.

(24) Wu, H.; Khan, M. A. J. Pharm. Sci. 2010, 99, 1516-1534.

(25) Nagy, Z. K.; Fevotte, G.; Kramer, H.; Simon, L. L. Chem. Eng. Res. Des. 2013, 91, 1903-1922.

(26) Nagy, Z. K.; Braatz, R. D. Annu. Rev. Chem. Biomol. Eng. 2012, 3, $55-75$.

(27) Yu, Z. Q.; Chew, J. W.; Chow, P. S.; Tan, R. B. H. Chem. Eng. Res. Des. 2007, 85, 893-905.

(28) Schaefer, C.; Lecomte, C.; Clicq, D.; Merschaert, A.; Norrant, E.; Fotiadu, F. J. Pharm. Biomed. Anal. 2013, 83, 194-201.

(29) Zhou, G.; Moment, A.; Yaung, S.; Cote, A.; Hu, T.-E. Org. Process Res. Dev. 2013, 17, 1320-1329.

(30) Helmdach, L.; Feth, M. P.; Minnich, C.; Ulrich, J. Chem. Eng. Process. 2013, 70, 184-197.

(31) Bro, R. Anal. Chim. Acta 2003, 500, 185-194.

(32) Kougoulos, E.; Jones, A. G.; Wood-Kaczmar, M. W. J. Cryst. Growth 2005, 273, 520-528.

(33) Wong, S. Y.; Tatusko, A. P.; Trout, B. L.; Myerson, A. S. Cryst. Growth Des. 2012, 12, 5701-5707.

(34) Saleemi, A. N.; Rielly, C. D.; Nagy, Z. K. Cryst. Growth Des. 2012, 12, 1792-1807.
(35) Abu Bakar, M. R.; Nagy, Z. K.; Saleemi, A. N.; Rielly, C. D. Cryst. Growth Des. 2009, 9, 1378-1384.

(36) Abu Bakar, M. R. Process Analytical Technology Based Approaches for the Monitoring and Control of Size and Polymorphic Form in Pharmaceutical Crystallisation Processes. Ph.D. Thesis, Loughborough University, 2010.

(37) Huang, J.; Romero-Torres, S.; Moshgbar, M. American Pharmaceutical Review, 2010.

(38) Hojjati, H.; Rohani, S. Org. Process Res. Dev. 2006, 10, 11011109.

(39) Thompson, C.; Davies, M. C.; Roberts, C. J.; Tendler, S. J. B.; Wilkinson, M. J. Int. J. Pharm. 2004, 280, 137-150.

(40) Hendriksen, B. A.; Grant, D. J. W.; Meenan, P.; Green, D. A. J. Cryst. Growth 1998, 183 (4), 629-640.

(41) Hendriksen, B. A.; Grant, D. J. W. J. Cryst. Growth 1995, 156, 252-260.

(42) Simone, E.; Saleemi, A. N.; Nagy, Z. K. Chem. Eng. Res. Des. 2014, 92, 594-611.

(43) Mark, H.; Workman, J., Jr. Spectroscopy 2003, 18, 32-37.

(44) Mark, H.; Workman, J., Jr. Spectroscopy 2004, 19, 44-51.

(45) Marbach, R.; Heise, H. M. Chemom. Intell. Lab. Syst. 1990, 9, $45-63$.

(46) Hemmateenejad, B.; Akhond, M.; Samari, F. Spectrochim. Acta, Part A 2007, 67, 958-965.

(47) Conzen, J. P. Multivariate Calibration: A Practical Guide for Method Development in Analytical Chemistry; BrukerOptik: Ettlingen, Germany, 2006.

(48) Alvarez, A. J.; Singh, A.; Myerson, A. S. Cryst. Growth Des. 2011 $11,4392-4400$

(49) Lawton, S.; Steele, G.; Shering, P.; Zhao, L.; Laird, I.; Ni, X.-W. Org. Process Res. Dev. 2009, 13, 1357-1363.

(50) Zhang, H.; Quon, J. L.; Alvarez, A. J.; Evans, J. M. B.; Myerson, A. S.; Trout, B. L. Org. Process Res. Dev. 2012, 16, 915-924.

(51) Hou, G.; Power, G.; Barrett, M.; Glennon, B.; Morris, G.; Zhao, Y. Cryst. Growth Des. 2014, 14, 1782-1793.

(52) Quon, J. L.; Zhang, H.; Alvarez, A. J.; Evans, J. M. B.; Myerson, A. S.; Trout, B. L. Cryst. Growth Des. 2012, 12, 3036-3044.

(53) Alvarez, A. J.; Myerson, A. S. Cryst. Growth Des. 2010, 10, 2219-2228

(54) Lee, T.; Chen, H. R.; Lin, H. Y.; Lee, H. L. Cryst. Growth Des. 2012, 12, 5897-5907.

(55) Simon, L. L.; Nagy, Z. K.; Hungerbuhler, K. Chem. Eng. Sci. 2009, 64 (14), 3344-3351.

(56) Simon, L. L.; Oucherif, K. A.; Nagy, Z. K.; Hungerbuhler, K. Ind. Eng. Chem. Res. 2010, 49, 9932-9944.

(57) Simon, L. L.; Merz, T.; Dubuis, S.; Lieb, A.; Hungerbuhler, K. Chem. Eng. Res. Des. 2012, 90, 1847-1855.

(58) Togkalidou, T.; Tung, H.-H.; Sun, Y.; Andrews, A.; Braatz, R. D. Org. Process Res. Dev. 2002, 6, 317-322.

(59) Wen, H.; Morris, K. R.; Park, K. Pharm. Res. 2008, 25, 349-358.

(60) Capes, J. S.; Cameron, R. E. CrystEngComm 2007, 9, 84.

(61) Ristic, R. I.; Finnie, S.; Sheen, D. B.; Sherwood, J. N. J. Phys. Chem. B 2001, 105 (38), 9057-9066.

(62) Wen, H.; Morris, K. R.; Park, K. J. Colloid Interface Sci. 2005, 290, 325-335.

(63) Li, L.; Lechuga-Ballesteros, D.; Szkudlarek, B. A.; RodriguezHornedo, N. J. Colloid Interface Sci. 1994, 168, 8-14.

(64) Borsos, Á.; Majumder, A.; Nagy, K. Proceedings of the 24th European Symposium on Computer Aided Process EngineeringESCAPE 24, Budapest, Hungary, June 15-18, 2014. 